\title{
Elimination Pathways of Fusion Protein and Peptide Drugs
}

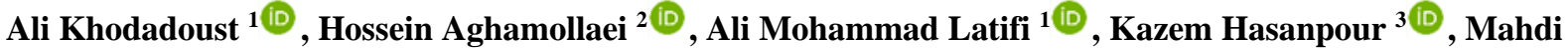 \\ Kamali $^{4}$ (i) , Hamid Tebyanian 5 (iD), Gholamreza Farnoosh 1,*iD

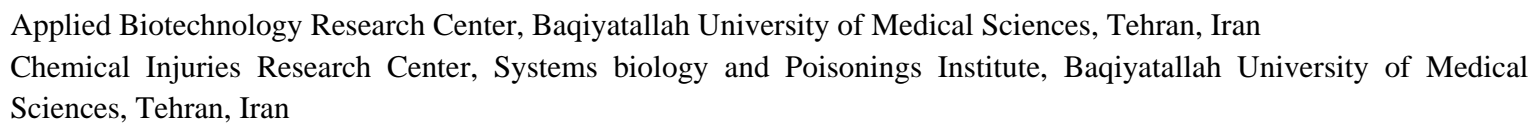

Scopus Author ID 55855454400

Received: 28.07.2020; Revised: 25.08.2020; Accepted: 27.08.2020; Published: 1.09.2020

\begin{abstract}
Fusion proteins have been known as an interesting subject for scientific researches in improving properties or making a new function by synergistically incorporating two protein domains into one complex. Fusion proteins are created by ligation of two or more protein domains in a single polypeptide with functional properties. Improvement of therapeutic function is one of the main goals for developing these products. Elimination from the body is one of the most important points that should be considered in the design and production of fusion proteins. This review describes some of the most important excretion/elimination pathways of fusion peptide and protein drugs as well as serious elimination challenges in the development and manufacturing of fusion proteins.
\end{abstract}

Keywords: Fusion proteins; Therapy; Pharmacokinetics; Serum half-life; Peptide.

(C) 2020 by the authors. This article is an open-access article distributed under the terms and conditions of the Creative Commons Attribution (CC BY) license (https://creativecommons.org/licenses/by/4.0/).

\section{Introduction}

Recombinant proteins have played a significant role in the treatment of several diseases as drugs over the last few decades. These proteins are mostly classified into natural analogs and protein fusions [1-4]. Human insulin (Humulin R) [3, 5] and etanercept (Enbrel) [6, 7] were approved as biopharmaceutical agents (by the FDA) in 1982 and 1998 from two groups (analogs and fused). Infusion proteins, one domain supplies a particular biological activity such as enzymatic activity (e.g., coagulation factors), target activation, or inactivation (e.g., the ligand for a receptor) and toxicity (e.g., diphtheria toxin). And also, other domains convey more general functions such as extending half-life, improving efficiency, reducing immunogenicity [8-11], increasing solubility, folding, stability, and/or thermostability as well as providing new targeting and delivery pathways [12-14].

Enhancing pharmacokinetic is an important part of the drug industry as a desirable improvement which can be obtained by fusing some domains to the target protein [15]. Fusion protein linkers have a key role in their efficiency. Direct fusion can lead to some unwanted results such as non-optimal bioactivity, misfolding, and low yield of product [16]. On the other hand, suitable linkers increase the stability/folding, the expression, improve the biological activity, enable targeting, and affect the pharmacokinetic( PK) of fusion proteins [17]. 
There are four critical parameters in the pharmacokinetic evaluation of therapeutic proteins such as Clearance (CL), Half-life (HL), Volume of Distribution (V), and Bioavailability (F) [18]. In other words, pharmacokinetic is a considerable part of drug absorption, distribution, metabolism (biotransformation), and elimination (ADME) [19, 20], and it was explained by Nelson in 1961 [21].

The significant factors are molecular size, conformation, charge, concentration, dosage, lipid solubility, hydrophilicity, and degree of ionization in ADME properties of drugs [22-24]. Clearance is the most important pharmacokinetic parameter and also quantifies the elimination of drugs. Therefore, the drug dose must be administered for the successful clinical application with protein therapeutics. Consequently, variations in drug clearance can lead to poor therapeutic results due to disease, genetics, and/or drug-drug interactions [25-27]. In this review, the recent important properties of linkers, linker's types, excretion/elimination pathways of fusion peptide and protein drugs were explained, and also, the serious elimination challenges were discussed in the development and manufacturing of fusion proteins.

\section{Fusion Proteins Linkers}

Linkers have a critical role in the functionality and bioactivity of fusion proteins. They can increase the stability/folding [28-30], expression [31], improve the biological activity [32], target to specific sites [33] as well as affect the PK of fusion proteins [34]. Amino acid residues, length, secondary structure, and hydrophobicity of linkers are the most important properties of linkers [17]. However, increasing the length of the linker can lead to an increase in the hydrophilicity and exposure in the aqueous solvent. On the other hand, the Förster resonance energy transfer (FRET) efficiency is decreased with an increase in linker length [35]. The combined use of hydrophilic and flexible residues inhibits the formation of secondary structures in linkers and then reduces the linker interference in the folding and function of the protein domains [35]. There are important amino acids in linker structures (approximately $50 \%$ ) such as polar uncharged or charged residues, specially threonine [36], serine (Ser), proline (Pro), glycine (Gly), phenylalanine (Phe). The composition and number of residues can be different based on the type of linker, and the structure of fused proteins such as Gly and Ser in flexible linkers, Pro, Lys, and Ala in rigid linkers as well as disulfide bonds in cleavage linker are more the important residues [17].

Table 1. Molecular weight as a major determinant of the elimination mechanisms of peptides and proteins.

Endocytosis may occur at any molecular weight range (modified from [41]).

\begin{tabular}{l|l|l|l} 
Molecular weight (Da) & Elimination site & Predominant elimination mechanisms & Major determinant \\
\hline$\leq 500$ & $\begin{array}{l}\text { Gastrointestinal tract, Blood, } \\
\text { Lysosomes, Liver }\end{array}$ & $\begin{array}{l}\text { Extracellular hydrolysis } \\
\text { Passive lipoid diffusion }\end{array}$ & $\begin{array}{l}\text { Structure, } \\
\text { lipophilicity }\end{array}$ \\
\hline $500-1000$ & Liver & $\begin{array}{l}\text { Carrier-mediated uptake } \\
\text { Passive lipoid diffusion }\end{array}$ & $\begin{array}{l}\text { Structure, } \\
\text { lipophilicity }\end{array}$ \\
\hline $1000-50000$ & kidney & $\begin{array}{l}\text { Glomerular filtration and subsequent } \\
\text { degradation process }\end{array}$ & Molecular weight \\
\hline $50000-200000$ & Liver, Kidney & Receptor-mediated endocytosis & Sugar, charge \\
\cline { 3 - 4 } & & Opsonisation & $\begin{array}{l}\alpha 2-\text { macroglobulin, } \\
\text { IgG }\end{array}$ \\
\cline { 3 - 4 } & & Phagocytosis & Particle aggregation
\end{tabular}

\section{The Elimination Pathways}

Drug excretion is the process of eliminating a drug from the body. The major elimination routes of fusion peptide and protein drugs are proteolysis, renal elimination, and 
hepatic elimination, as similar to other therapeutic proteins and peptides as well as receptormediated endocytosis [33].

However, excretion is also possible via secondary routes such as lungs, breast milk [37], saliva [38], tears [39], and sweat [26]. The route of degradation and elimination for peptide/protein is dependent on several factors, including molecular weight (table 1), secondary-tertiary structure, level of glycosylation, overall charge, lipophilicity, functional groups like the natural trend for particle aggregation [40].

\section{Proteolysis Elimination}

Proteolytic enzymes are ever-present in the body. Therefore, peptide and protein metabolisms are performed in classical clearance organs (e.g., bone, oral, and gastrointestinal) as well as blood cells and other body tissues [42-46]. Peptides and small proteins are unstable in body fluids, and also, there is no easy pass from the membrane and rapidly broken down by peptidases with short elimination half-life, and also, the ranging takes from several minutes to several hours [22, 47]. Many modification approaches have been used for overcoming this challenge, such as engineering of natural enzymes [12], conjugating to macro-molecules or their domains (e.g., human serum albumin, polyethylene glycol, XTEN polymers, transferrin, homo amino acid polymer, proline-alanine-serine polymer, elastin-like peptide, carboxyterminal peptide, IgGs and $\mathrm{Fc}$ ) [8] and stabilizing peptides/proteins upon fabrication in hydrogels [48] which causes a less accessible to protease digestion, leading to extended elimination half-life. The lysosomal and the ubiquitin-mediated pathways work together in the degradation of intracellular and exogenous proteins.

\section{Renal Elimination}

The kidney has physiologic roles (e.g., mineral composition, regulation of fluid volume, and acidity) with several functional roles. The functional role of the kidney is the elimination of drugs and their metabolites from the body as the main excretion route of drug clearance. The kidney is the main organ for the clearance of polar water-soluble chemicals. Renal drug excretion is done through three basic processes: glomerular filtration, tubular secretion, and tubular reabsorption [49]. The first two processes serve to draw out the drug from the blood into the urine. In the last process, tubular reabsorption involves the returned drug back into the blood. Therefore, the correlative contributions of these three mechanisms are important in renal drug excretion [26]. More detailed information about these three processes was reported previously [50]. Molecular size and electrical charge are two key parameters in kidney filtration of peptide and protein drugs [22, 26, 49]. Glomerular filtration is an effective mechanism for renal elimination of small proteins (smaller than $30 \mathrm{kDa}$ and specially $<5 \mathrm{kDa}$ ), while renal elimination of higher molecular weight proteins $(>30 \mathrm{kDa})$ is very low [51]. The maximum rate of renal elimination (via glomerular filtration) is related to peptides and proteins with a molecular weight of less than $5 \mathrm{kDa}(\sim 120 \mathrm{~mL} / \mathrm{min}$ in humans) [52]. The other effective factors in renal excretion of drugs include alteration of urine $\mathrm{pH}$ and diuresis, protein binding of the drug (Limits glomerular filtration without limitation in active tubular secretion), and age (Glomerular filtration rate declines slowly with age) [53]. The increasing molecular weight and negative charge of fusion proteins can be able to decrease the renal/proteolysis elimination and lead to extended plasma half-life. 
The increasing elimination through proteolysis leads to a sharp decrease in total clearance from the renal route as a non-specific degradation pathway throughout the body. However, the low metabolic activity of proteins may lead to $100 \%$ renal contribution in the clearance in other tissues or limits in distribution to the extravascular space [54] Parkes et al. demonstrated that renal elimination is a majority clearance pathway in exenatide as a peptidaseresistance peptide [55].

\section{Hepatic Elimination}

Elimination of drugs via the Hepatic route includes a series of events involving uptake them from the blood flow into one of three cell types in the liver (endothelial cells, hepatocytes, and Kupffer cell) that it leads to intracellular metabolism and/or excretion [26]. Generally, the Hepatic pathway is an important route for the elimination of small therapeutic drugs as the renal excretion route and is not a significant pathway for fusion protein elimination. However, hepatic elimination may be an important route for clearance of fusion proteins comprising protein domains that are metabolized in the liver, such as tissue plasminogen [56] and insulin [57].

\section{Target-Mediated Drug Disposition (TMDD)/Receptor-Mediated Endocytosis (RME)}

Target-mediated drug disposition is described as receptor-mediated endocytosis [33] that has an important role in the disposition of healing peptide/protein drugs in the body [58] . High-affinity and low-capacity binding of receptors to endogenous or exogenous ligand (e.g., therapeutic peptide/protein or their domains) may lead to cellular uptake by receptor-mediated endocytosis and subsequent intracellular lysosomal degradation [59]. RME is supposed to be an important elimination route for fusion peptide/protein drugs that bind to their receptors on the cell surfaces and lead to a loss of plasma concentration and/or elimination [22]. For example, the interleukin-1 domain binds to the IL-1 receptor on the cell surface is internalized and degraded through RME [36]. In addition to receptors, other targets can also be used as mediators. The Fab portion of some mAbs (e.g., rituximab) binds to the target epitopes on the cell surface and is degraded via ADCC (antibody-dependent cellular cytotoxicity) [60]. The TMDD elimination route can be saturated with therapeutic concentrations and decreases with increasing dose due to the limitation in target receptors number. Therefore, fusion proteins are affected by TMDD with protein drug domains, and also, it may display nonlinearity in their PK profiles and exhibit a dose-dependent plasma half-life [22].

\section{Elimination via NonSpecific Fc Receptors (FcyRs and FcRns)}

In the Fc region, $\mathrm{Fc} \gamma \mathrm{R}$ is located between the $\mathrm{CH}_{1}$ and $\mathrm{CH}_{2}$ domains and has a critical role for antibody effector functions. But, $\mathrm{FcRn}$ is located between the $\mathrm{CH}_{2}$ and $\mathrm{CH}_{3}$ domains and has an important in recycling of antibodies for a long half-life [61]. Fc $\gamma$ Rs can be applied as a mediator in therapeutic peptide/protein drug elimination via binding, incorporation, and eventually degradation of $\mathrm{IgG}$ by lysosomes and/or phagocytic cells [62]. Elimination via Fc $\gamma \mathrm{R}$ can be an important route when an antibody can form soluble immune complexes via fusion processes and may play a significant role when an antibody binds to suspended cells in blood or other body fluids [63]. The elimination pathway by FcRn is a pH-dependent process. The FcRn binds to the Fc part of IgG in the slightly acidic ( $\sim 6.0)$ environment of the endosomes. Then, The FcRn-IgG complex is carried back to the cell surface and released into the systemic 
circulation at neutral $\mathrm{pH}$ (7-7.4), whereas unbound IgG and other proteins are changed to amino acids by intracellular lysosomes. Also, FcRn has important roles in increasing the half-life of drugs and elimination as a salvage route [60].

\section{Elimination Challenges for Fusion Proteins}

Protein fusing technology may be able to minimize the main elimination pathways (proteolysis, renal and hepatic routes) as DNA-based genetic engineering technology and lead to improving the critical therapeutic properties of drugs such as half-life, stability, and activity as well as solubility. In other words, some significant limitations affect the development of fusion proteins as therapeutics.

\section{PK of Bifunctional Fusion Proteins}

Since fusion proteins are combined from at least two domains and the pharmacokinetics of fusion proteins is intricated more than single-domain proteins [22]. On another side, the effect of domains (elimination mechanisms, intracellular processing, and receptor binding on plasma half-life of fusion proteins) cannot be determined if there is no precise and complete understanding of the effect of domains on each other. So, there is no complete analysis of PK of fusion proteins, and also, the fusion proteins design cannot be easy with the optimal characteristics such as stability, solubility as well as the probability of success (POS).

\section{Misfolding of Fusion Proteins}

The overexpression of many fusion proteins may also lead to their misfolding in host cells and form insoluble aggregates $[64,65]$. The misfolded fusion proteins are unstable and eliminate via a rapid degradation as therapeutics. There are common strategies that can be used to prevent degradation, such as co-administration of fusion proteins with enzyme inhibitors and encapsulation of fusion proteins with inert and biocompatible polymers [66].

\section{Immunogenicity}

Fusion proteins may also make new/unknown epitopes that follow immunogenicity, strong hypersensitivity, or an immune response due to half-life decreasing [1]. The storage condition may also cause immunogenicity as well as structural features of fusion proteins [66]. Therefore, it can be suggested that the perfect analysis of structural features such as sequence modification and/or variation by immunogenicity and toxicity tests.

\section{Conclusion}

The fusion proteins are a growing segment of the biologics markets in the drug industry. Proteolysis is considered to be the main elimination route for many therapeutic protein drugs, hepatic and renal routes. Drug clearance is not an important pathway for the elimination of fusion proteins via these routes. Moreover, receptor-mediated endocytosis/Target-Mediated Drug Disposition (TMDD), as well as non-specific Fc Receptors (Fc $\gamma$ Rs and FcRns), are the main clearance pathway for most therapeutic fusion proteins that have high specific binding to their targets. The half-life of a protein is considerably affected by the chemical structure of the $\mathrm{N}$-terminal and/or C-terminal amino acid. Therefore, attention to type and arrangement of N- 
terminal and C-terminal amino acids certainly leads to the proper design of fusion proteins with the optimal characteristics such as stability, solubility, probability of success (POS) as well as effective clearance from suitable elimination pathway.

\section{Funding}

This research received no external funding.

\section{Acknowledgments}

The authors would like to thank Baqiyatallah University of Medical Sciences, Tehran, Iran.

\section{Conflicts of Interest}

The authors declare no conflict of interest.

\section{References}

1. Schmidt, S.R. Fusion protein technologies for biopharmaceuticals: applications and challenges. John Wiley \& Sons, 2013; https://doi.org/10.1002/9781118354599.

2. Caravella, J.; Lugovskoy, A. Design of next-generation protein therapeutics. Current opinion in chemical biology 2010, 14, 520-528, https://doi.org/10.1016/j.cbpa.2010.06.175.

3. Leader, B.; Baca, Q.J.; Golan, D.E. Protein therapeutics: a summary and pharmacological classification. Nature reviews Drug discovery 2008, 7, 21-39, https://doi.org/10.1038/nrd2399.

4. Noroozi-Aghideh, A.; Kheirandish, M. Human cord blood-derived viral pathogens as the potential threats to the hematopoietic stem cell transplantation safety: A mini review. World J Stem Cells 2019, 11, 73-83, https://doi.org/10.4252/wjsc.v11.i2.73.

5. Rosenfeld, L. Insulin: discovery and controversy. Clinical chemistry 2002, 48, 2270-2288, https://doi.org/10.1093/clinchem/48.12.2270.

6. Azevedo, V.F.; Galli, N.; Kleinfelder, A.; D’Ippolito, J.; Urbano, P.C. Etanercept biosimilars. Rheumatology international 2015, 35, 197-209, https://doi.org/10.1007/s00296-014-3080-5.

7. Haraoui, B.; Bykerk, V. Etanercept in the treatment of rheumatoid arthritis. Therapeutics and clinical risk management 2007, 3, 99-105, https://dx.doi.org/10.2147\%2Ftcrm.2007.3.1.99.

8. Strohl, W.R. Fusion proteins for half-life extension of biologics as a strategy to make biobetters. BioDrugs 2015, 29, 215-239, https://doi.org/10.1007/s40259-015-0133-6.

9. Verma, S.; Jain, P.; Chauhan, P. Biobetters: the better biologics and their regulatory overview. International Journal of Drug Regulatory Affairs 2016, 4, 13-20, https://doi.org/10.22270/ijdra.v4i1.177.

10. Noroozi-Aghideh, A.; Kashani khatib, Z.; Naderi, M.; Dorgalaleh, A.; Yaghmaie, M.; Paryan, M.; Alizadeh, S. Expression and $\mathrm{CpG}$ island methylation pattern of MMP-2 and MMP-9 genes in patients with congenital factor XIII deficiency and intracranial hemorrhage. Hematology 2019, 24, 601-605, https://doi.org/10.1080/16078454.2019.1654181.

11. Khojaste, M.; Yazdanian, M.; Tahmasebi, E.; Shokri, M.; Houshmand, B.; Shahbazi, R. Cell Toxicity and inhibitory effects of Cyperus rotundus extract on Streptococcus mutans, Aggregatibacter actinomycetemcomitans and Candida albicans. Eur $J$ Transl Myol 2018, 28, 7917, https://doi.org/10.4081/ejtm.2018.7917.

12. Farnoosh, G.; Latifi, A.M.; Khajeh, K.; Aghamollaei, H.; Najafi, A. Enzymatic degradation of organophosphate compounds: evaluation of high-level production, solubility and stability. Journal of Applied Biotechnology Reports 2016, 2, 339-344.

13. Farnoosh, G.; Khajeh, K.; Latifi, A.M.; Aghamollaei, H. Engineering and introduction of de novo disulphide bridges in organophosphorus hydrolase enzyme for thermostability improvement. Journal of biosciences 2016, 41, 577-588, https://doi.org/10.1007/s12038-016-9643-8.

14. Suzuki, E.; Daniels, T.R.; Helguera, G.; Penichet, M.L.; Umezawa, K.; Bonavida, B. Inhibition of NF-кB and Akt pathways by an antibody-avidin fusion protein sensitizes malignant B-cells to cisplatin-induced apoptosis. International journal of oncology 2010, 36, 1299-1307, https://doi.org/10.3892/ijo_00000615.

15. Gloff, C.A.; Benet, L.Z. Pharmacokinetics and protein therapeutics. Advanced Drug Delivery Reviews 1990, 4, 359-386, https://doi.org/10.1016/0169-409X(90)90027-P.

16. Paraskevopoulou, V.; Falcone, F. Polyionic tags as enhancers of protein solubility in recombinant protein expression. Microorganisms 2018, 6, https://doi.org/10.3390/microorganisms6020047.

17. Chen, X.; Zaro, J.L.; Shen, W.-C. Fusion protein linkers: property, design and functionality. Advanced Drug Delivery Reviews 2013, 65, 1357-1369, https://doi.org/10.1016/j.addr.2012.09.039. 
18. Kontermann, R.E. Strategies for extended serum half-life of protein therapeutics. Current opinion in biotechnology 2011, 22, 868-876, https://doi.org/10.1016/j.copbio.2011.06.012.

19. Vugmeyster, Y.; Xu, X.; Theil, F.-P.; Khawli, L.A.; Leach, M.W. Pharmacokinetics and toxicology of therapeutic proteins: advances and challenges. World journal of biological chemistry 2012, 3.

20. Vugmeyster, Y.; Harrold, J.; Xu, X. Absorption, distribution, metabolism, and excretion (ADME) studies of biotherapeutics for autoimmune and inflammatory conditions. The AAPS journal 2012, 14, 714-727, https://dx.doi.org/10.1208\%2Fs12248-012-9385-y.

21. Nelson, E. Kinetics of drug absorption, distribution, metabolism, and excretion. Journal of pharmaceutical sciences 1961, 50, 181-192, https://doi.org/10.1002/jps.2600500302.

22. Chen, X.; Zaro, J.L.; Shen, W.-C. Pharmacokinetics of recombinant bifunctional fusion proteins. Expert opinion on drug metabolism \& toxicology 2012, 8, 581-595, https://doi.org/10.1517/17425255.2012.673585.

23. Chillistone, S.; Hardman, J. Factors affecting drug absorption and distribution. Anaesthesia \& Intensive Care Medicine 2008, 8, 335-339, https://doi.org/10.1016/j.mpaic.2017.04.007.

24. Tibbitts, J.; Canter, D.; Graff, R.; Smith, A.; Khawli, L.A. Key factors influencing ADME properties of therapeutic proteins: A need for ADME characterization in drug discovery and development. $m A b s$ 2016, 8 , 229-245, https://doi.org/10.1080/19420862.2015.1115937.

25. Lee, J.; Kim, A.; Yu, K.-S.; Chung, J.-Y.; Yim, S.-V.; Kim, B.-H. Pharmacokinetics and bioequivalence of two different $20 \mathrm{mg}$ olmesartan tablets: A randomized, single-dose, two-period crossover study in healthy Korean male volunteers. Translational and Clinical Pharmacology 2015, 23, 49-53, https://doi.org/10.12793/tcp.2015.23.2.49.

26. Hacker, M.; Messer, W.S.; Bachmann, K.A., Pharmacology: principles and practice. 2009: Academic Press.

27. Hassani, H.; Khoshdel, A.; Sharifzadeh, S.R.; Heydari, M.F.; Alizadeh, S.; Aghideh, A.N. TNF- $\alpha$ and TGFB level after intraoperative allogeneic red blood cell transfusion in orthopedic operation patients. Turk J Med Sci 2017, 47, 1813-1818, https://doi.org/10.3906/sag-1508-36.

28. He, R.; Finan, B.; Mayer, J.P.; DiMarchi, R.D. Peptide Conjugates with Small Molecules Designed to Enhance Efficacy and Safety. Molecules 2019, 24, https://dx.doi.org/10.3390\%2Fmolecules24101855.

29. Anami, Y.; Yamazaki, C.M.; Xiong, W.; Gui, X.; Zhang, N.; An, Z.; Tsuchikama, K. Glutamic acid-valinecitrulline linkers ensure stability and efficacy of antibody-drug conjugates in mice. Nature communications 2018, 9, https://doi.org/10.1038/s41467-018-04982-3.

30. Yang, G.; Xu, X.; Ding, Y.; Cui, Q.; Wang, Z.; Zhang, Q.; Shi, S.; Lv, Z.; Wang, X.; Zhang, J. Linker length affects expression and bioactivity of the onconase fusion protein in Pichia pastoris. Genet. Mol. Res 2015, 14, 19360-19370, https://doi.org/10.4238/2015.december.29.46.

31. Amet, N.; Lee, H.-F.; Shen, W.-C. Insertion of the designed helical linker led to increased expression of tfbased fusion proteins. Pharmaceutical research 2009, 26, 523-8, https://doi.org/10.1007/s11095-008-97670 .

32. Guo, H.; Yang, Y.; Xue, F.; Zhang, H.; Huang, T.; Liu, W.; Liu, H.; Zhang, F.; Yang, M.; Liu, C. Effect of flexible linker length on the activity of fusion protein 4-coumaroyl-CoA ligase:: stilbene synthase. Molecular BioSystems 2017, 13, 598-606, https://doi.org/10.1039/c6mb00563b.

33. Hutt, M.; Fellermeier-Kopf, S.; Seifert, O.; Schmitt, L.C.; Pfizenmaier, K.; Kontermann, R.E. Targeting scFv-Fc-scTRAIL fusion proteins to tumor cells. Oncotarget 2018, 9, 11322-11335, https://doi.org/10.18632/oncotarget.24379.

34. Chen, X.; Lee, H.-F.; Zaro, J.L.; Shen, W.-C. Effects of receptor binding on plasma half-life of bifunctional transferrin fusion proteins. Molecular pharmaceutics 2011, 8, 457-465, https://doi.org/10.1021/mp1003064.

35. van Rosmalen, M.; Krom, M.; Merkx, M. Tuning the flexibility of Glycine-Serine linkers to allow rational design of multidomain proteins. Biochemistry 2017, 56, 6565-6574, https://doi.org/10.1021/acs.biochem.7b00902.

36. Hoffman, H.M.; Throne, M.L.; Amar, N.; Sebai, M.; Kivitz, A.J.; Kavanaugh, A.; Weinstein, S.P.; Belomestnov, P.; Yancopoulos, G.D.; Stahl, N. Efficacy and safety of rilonacept (interleukin-1 Trap) in patients with cryopyrin-associated periodic syndromes: results from two sequential placebo-controlled studies. Arthritis \& Rheumatism 2008, 58, 2443-2452.

37. Ito, S.; Lee, A. Drug excretion into breast milk—overview. Advanced Drug Delivery Reviews 2003, 55, 617627, https://doi.org/10.1016/S0169-409X(03)00034-6.

38. Idkaidek, N.; Arafat, T. Saliva versus plasma pharmacokinetics: theory and application of a salivary excretion classification system. Molecular pharmaceutics 2012, 9, 2358-2363, https://doi.org/10.1021/mp300250r.

39. Van Haeringen, N. Secretion of drugs in tears. Current Eye Research 1985, 4, 485-488, https://doi.org/10.3109/02713688509025164.

40. Andus, K.L.; Raub, T.L. Biological barriers to protein delivery. Volume 4, Springer Science \& Business Media, 2012; https://doi.org/10.1007/978-1-4615-2898-2.

41. Braeckman, R.; Meibohm, B. Pharmacokinetics and pharmacodynamics of peptide and protein drugs. In: Pharmaceutical biotechnology. CRC Press, 2016; pp. 107-135.

42. Di, L. Strategic approaches to optimizing peptide ADME properties. The AAPS journal 2015, 17, 134-143, https://doi.org/10.1208/s12248-014-9687-3. 
43. Esfahanizadeh, N.; Motalebi, S.; Daneshparvar, N.; Akhoundi, N.; Bonakdar, S. Morphology, proliferation, and gene expression of gingival fibroblasts on Laser-Lok, titanium, and zirconia surfaces. Lasers Med Sci 2016, 31, 863-73, https://doi.org/10.1007/s10103-016-1927-6.

44. Esfahanizadeh, N.; Daneshparvar, P.; Takzaree, N.; Rezvan, M.; Daneshparvar, N. Histologic Evaluation of the Bone Regeneration Capacities of Bio-Oss and MinerOss X in Rabbit Calvarial Defects. Int J Periodontics Restorative Dent 2019, 39, e219-e227, https://doi.org/10.11607/prd.4181.

45. Esfahanizadeh, N.; Yousefi, H. Successful Implant Placement in a Case of Florid Cemento-Osseous Dysplasia: A Case Report and Literature Review. J Oral Implantol 2018, 44, 275-279, https://doi.org/10.1563/aaid-joi-D-17-00140.

46. Daneshparvar, H.; Sadat-Shirazi, M.S.; Fekri, M.; Khalifeh, S.; Ziaie, A.; Esfahanizadeh, N.; Vousooghi, N.; Zarrindast, M.R. NMDA receptor subunits change in the prefrontal cortex of pure-opioid and multi-drug abusers: a post-mortem study. Eur Arch Psychiatry Clin Neurosci 2019, 269, 309-315, https://doi.org/10.1007/s00406-018-0900-8.

47. Verhoef, J.; Bodde, H.; De Boer, A.; Bouwstra, J.; Junginger, H.; Merkus, F.; Breimer, D. Transport of peptide and protein drugs across biological membranes. European journal of drug metabolism and pharmacokinetics 1990, 15, 83-93, https://doi.org/10.1007/BF03190191.

48. Raza, F.; Zafar, H.; Zhu, Y.; Ren, Y.; Ullah, A.; Khan, A.; He, X.; Han, H.; Aquib, M.; Boakye-Yiadom, K. A review on recent advances in stabilizing peptides/proteins upon fabrication in hydrogels from biodegradable polymers. Pharmaceutics 2018, 10, https://doi.org/10.3390/pharmaceutics10010016.

49. Caliceti, P.; Veronese, F.M. Pharmacokinetic and biodistribution properties of poly (ethylene glycol)protein conjugates. Advanced Drug Delivery Reviews 2003, 55, 1261-1277, https://doi.org/10.1016/S0169409X(03)00108-X.

50. Meibohm, B.; Derendorf, H. Pharmacokinetics and pharmacodynamics of biotech drugs. Oliver Kayser, Rainer H. Muller 2004, 147, https://doi.org/10.1002/9783527609628.

51. Kompella, U.B.; Lee, V.H. Pharmacokinetics of peptide and protein drugs. In: Peptide and protein drug delivery. Marcel Dekker New York, 1991; pp. 391-484.

52. Maack, T.; Johnson, V.; Kau, S.T.; Figueiredo, J.; Sigulem, D. Renal filtration, transport, and metabolism of low-molecular-weight proteins: a review. Kidney international 1979, 16, 251-270, https://doi.org/10.1038/ki.1979.128.

53. Regårdh, C.G. Factors contributing to variability in drug pharmacokinetics. IV. Renal excretion. Journal of Clinical Pharmacy and Therapeutics 1985, 10, 337-349.

54. Lin, J.H. Pharmacokinetics of biotech drugs: peptides, proteins and monoclonal antibodies. Current drug metabolism 2009, 10, 661-691.

55. Parkes, D.; Jodka, C.; Smith, P.; Nayak, S.; Rinehart, L.; Gingerich, R.; Chen, K.; Young, A. Pharmacokinetic actions of exendin-4 in the rat: comparison with glucagon-like peptide-1. Drug Development Research 2001, 53, 260-267, https://doi.org/10.1002/ddr.1195.

56. Smedsrød, B.; Einarsson, M. Clearance of tissue plasminogen activator by mannose and galactose receptors in the liver. Thrombosis and haemostasis 1990, 63, 060-066.

57. Authier, F.O.; Danielsen, G.M.; Kouach, M.; Briand, G.; Chauvet, G.V. Identification of insulin domains important for binding to and degradation by endosomal acidic insulinase. Endocrinology 2001, 142, 276289.

58. Mager, D.E. Target-mediated drug disposition and dynamics. Biochemical pharmacology 2006, 72, 1-10, https://doi.org/10.1016/j.bcp.2005.12.041.

59. Krippendorff, B.-F.; Kuester, K.; Kloft, C.; Huisinga, W. Nonlinear pharmacokinetics of therapeutic proteins resulting from receptor mediated endocytosis. Journal of pharmacokinetics and pharmacodynamics 2009 , 36, 239-260, https://dx.doi.org/10.1007\%2Fs10928-009-9120-1.

60. Ryman, J.T.; Meibohm, B. Pharmacokinetics of monoclonal antibodies. CPT: pharmacometrics \& systems pharmacology 2017, 6, 576-588, https://dx.doi.org/10.1002\%2Fpsp4.12224.

61. Liu, L. Pharmacokinetics of monoclonal antibodies and Fc-fusion proteins. Protein \& cell 2017, 1-18, https://doi.org/10.1007/s13238-017-0408-4.

62. Leabman, M.K.; Meng, Y.G.; Kelley, R.F.; DeForge, L.E.; Cowan, K.J.; Iyer, S. Effects of altered Fc $\gamma$ R binding on antibody pharmacokinetics in cynomolgus monkeys. MAbs. Taylor \& Francis 2013, 5, 896-903, https://dx.doi.org/10.4161\%2Fmabs.26436.

63. Kasturirangan, S.; Rainey, G.J.; Xu, L.; Wang, X.; Portnoff, A.; Chen, T.; Fazenbaker, C.; Zhong, H.; Bee, J.; Zeng, Z. Targeted Fc $\gamma$ R mediated clearance by a biparatopic bispecific antibody. Journal of Biological Chemistry 2017, 292, 4361-4370, https://dx.doi.org/10.1074\%2Fjbc.M116.770628.

64. Thomas, J.G.; Baneyx, F. Protein misfolding and inclusion body formation in recombinant Escherichia coli cells overexpressing heat-shock proteins. Journal of Biological Chemistry 1996, 271, 11141-11147, https://doi.org/10.1074/jbc.271.19.11141.

65. de Marco, A.; Deuerling, E.; Mogk, A.; Tomoyasu, T.; Bukau, B. Chaperone-based procedure to increase yields of soluble recombinant proteins produced in E. coli. BMC biotechnology 2007, 7, https://dx.doi.org/10.1186\%2F1472-6750-7-32. 
66. Akash, M.S.H.; Rehman, K.; Tariq, M.; Chen, S. Development of therapeutic proteins: advances and challenges. Turkish Journal of Biology 2015, 39, 343-358, https://doi.org/10.3906/biy-1411-8. 